\title{
Estudio de seis piezas arqueologicas en soportes óseos de origen paleontologicos, identificadas al Período Arcaico Tardío (2500 a.C.) provenientes del Valle Chicama, Región La Libertad - Perú
}

\section{Study of six archaeological pieces in paleontological bone supports, identified in the Late Archaic Period (2500 BC) from the Chicama Valley, La Libertad Region - Peru}

\author{
Daniel S. Castillo Benítez
}

\section{RESUMEN}

El presente artículo tiene como objetivo el estudio de seis piezas óseas de origen paleontológico provenientes del valle Chicama, Región La Libertad, Perú, la investigación respondio al diseño descriptivo cuya finalidad fue caracterizar cronológica e iconográfica a dichas piezas, utilizando la tecnica de registro y documentación, atreves de ellos se logro encontrar que este material pertenece al Período Arcaico Tardío.

Palabras clave: soportes óseos, paleontología, estilo Sechín.

\begin{abstract}
The objective of this article is the study of six pieces abroad of paleontological origin from the Chicama Valley, La Libertad Region, Peru, the investigation of response to the descriptive design whose determination was characterized by chronological and iconographic to various pieces. The registration and documentation technique is documented. It was found that this material belongs to the Late Archaic Period.
\end{abstract}

Keywords: bone supports, palaeontology, Sechin style.

'Arqueólogo. Instituto de Investigación de Arqueología y Antropología “Kuélap” de la Universidad Nacional Toribio Rodríguez de Mendoza deAmazonas. Correo electrónico: daniel.castillo@untrm.edu.pe. 


\section{INTRODUCCIÓN}

A través del estudio de los restos óseos de origen paleontologico que fueron analizados, se plantea que la utilización de dichos soportes, formaron parte de una parafernalia elaboradas para actividades rituales. La investigación se justifica en la relevancia que estos presentan por la intervención de la mano del hombre.

Respecto a las investigaciones previas que se tienen para el valle Chicama y reportadas en Huaca Prieta por Junios Bird (1985), da cuenta de la presencia de un arte primitivo que está presente desde la época muy temprana y relacionada al Precerámico costeño, versando de una profusión visual contenida en textiles y mates o calabazas presentando dichos soportes como un arte primigenio de esta época.

Entre los referentes analógicos en el valle, se cuenta con el reporte que hiciera Enrique Vergara (1990), respecto a una espátula cubierta con resagos de cinabrio, pieza que fue adquirida por el Museo de Arqueología, Antropología e Historia de la Universidad Nacional de Trujillo en 1957 y fue descrita: "personaje masculino cuyo cuerpo está en forma frontal, y tiene en perfil los brazos a la altura del pecho, cuyos dedos terminan en pronunciadas uñas; mientras la cabeza se encuentra en perfil, de labios y nariz engrosados, el ojo tiene forma elíptica" considerada para el Período Formativo (Vergara, 1990: 112).

Si bien no se tiene noticia del contexto de la mencionada espátula, permite de alguna manera considerarla dentro de los precedentes de hallazgos de características similares, en razon a que dichos testimonios arqueológicos fueron encontrados fortuitamente en la parte sur del valle Chicama.

\section{MATERIAL Y MÉTODOS}

El objeto de estudio trata de seis soportes óseos, tres de ellos pertenecerían a probables mascaras y otros tres identificados como colgantes, los primeros fragmentos revelan solidez por presentar consistencia gruesa y por su tamaño dejan entrever que se tratarían de restos óseos de origen paleontológicos manufacturados por la mano del hombre. Mientras que los colgantes revelan una consistencia mucho más delgada o fina, y una conformación alargada con curvatura de origen, siendo factible que estos soportes óseos pertenezcan a una cavidad craneal de algún animal.

Se presenta un cuadro con las medidas de altura y ancho, así como el peso de cada una de las piezas óseas que fueron registradas.

Se trata de un soporte óseo de conformación casi

\begin{tabular}{|c|c|c|}
\hline \multicolumn{3}{|c|}{ MASCARAS } \\
\hline SOPORTE A & SOPORTE B & SOPORTEC \\
\hline $15 \times 13 \mathrm{~cm}$ & $10 \times 7 \mathrm{~cm}$ & $9.6 \times 15 \mathrm{~cm}$ \\
\hline $172 \mathrm{grs}$. & $74 \mathrm{grs}$ & 10 grs. \\
\hline
\end{tabular}

\section{SOPORTE A}

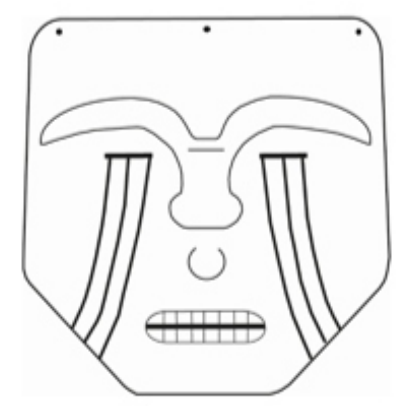

Lamina $\mathrm{N}^{\circ} 3$ Mascara con lagrimales al estilo Sechín.

cuadrada y plana, cuya medida es de $15 \mathrm{~cm}$ de altura, $13 \mathrm{~cm}$ de ancho y con un peso de 172 grs., su espesor alcanza más de $1 \mathrm{~cm}$., el soporte conserva los extremos de sus bordes redondeados, denotando que la superficie habia sido rebajada en ambos lados. La parte superior del soporte presenta tres orificios distribuidos en forma regular con una ligera verticalidad y apenas denotan desgaste. En el soporte fue labrado un rostro antropomorfo, cuyo delineado en las cejas fueron elaboradas en relieve, muestra ojos achinados con una abertura calada y estrecha cuyo alrededor fue cubierta con una coloración de rojo carmín que se distribuyen a lo largo de las ranuras que bajan a modo de lagrimales. Se suma una nariz pequeña en forma chata y ancha, una boca cuya abertura denotan dientes cortos y rectangulares que también fueron calados. El estado de conservación del soporte óseo se encuentra fracturado, contabilizándose un total de 10 fragmentos, presentando algunos faltantes intermedios, los fragmentos revelan cierta porosidad y astillados en un lado, debido a haber estado expuesta a factores eólicos.

\section{SOPORTE B}

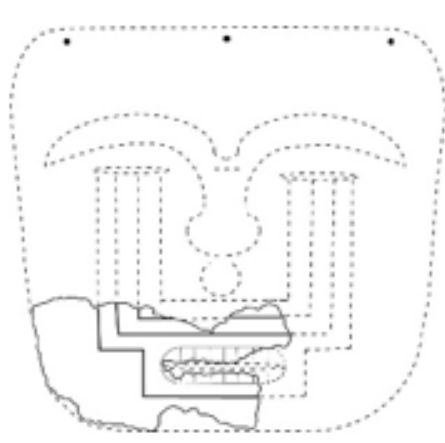

Lamina $\mathrm{N}^{\circ} 4$ Mascara con modelo rectilineo de los 
Este soporte presenta una textura mucho más irregular y diferente a la primera pieza, debido a su estado de conservación y por encontrarse sumamente fragmentado, se contabilizo un total de 18 fragmentos que se encontraban astillados, y varios de ellos fueron adheridos para su estabilidad. Sus medidas alcanza los $10 \mathrm{~cm}$ de altura y $7 \mathrm{~cm}$ de largo, con $10 \mathrm{~mm}$ de ancho y un peso de 74 grs.

El soporte expone una disposición mucho más plana con relación a sus relieves, fue notoria una decoración facial de líneas rectas dispuestas entre la cara y la boca, presentando una abertura calada en la que destacan 8 pares de dientes. La pieza con una textura ósea mucho más porosa que la anterior y un estado de conservación mucho más frágil.

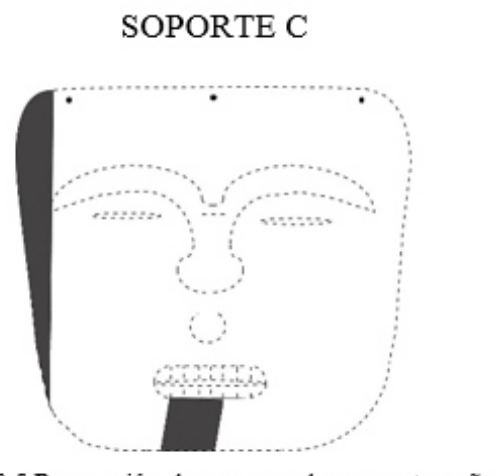

Lamina $\mathrm{N}^{\circ} 5$ Proyección de mascara de menor tamaño

De este soporte se identificó solamente 2 fragmentos pertenecientes a la misma textura uniforme y de conformación semejante comparativamente al primer soporte, lo diferencial son sus dimensiones. Se tomó como referente a un fragmento cuya dimensión muestra que se trata del lado derecho alcanzando $9.6 \mathrm{~cm}$ de altura, $15 \mathrm{~cm}$ de largo y $7 \mathrm{~mm}$ de ancho con un peso de 10 grs. No existiendo más fragmentos que una parte central de lo que fuera el soporte.

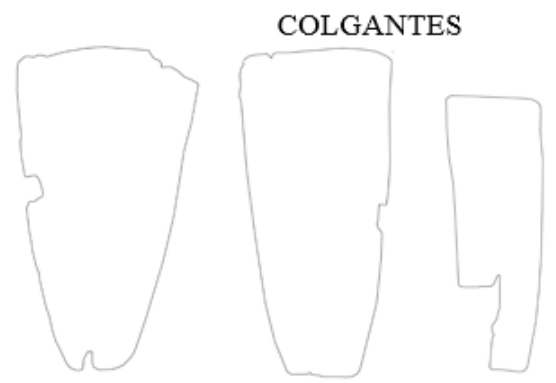

Lamina $\mathrm{N}^{\circ} 6$ Colgantes con orificios en sus extremos

\begin{tabular}{|c|c|c|}
\hline \multicolumn{3}{|c|}{ COLGANTES } \\
\hline COLGANTEA & COLGANTE B & COLGANTE C \\
\hline 6 fragmentos & 9 fragmentos & 4 fragmentos \\
\hline $13 \mathrm{~cm}$ altura & $14 \mathrm{~cm}$ altura & $12.5 \mathrm{~cm}$ altura 3.5 \\
$7 \mathrm{~cm}$ largo & $5.5 \mathrm{~cm}$ largo & $\mathrm{cm}$ largo \\
$3 \mathrm{~mm}$ ancho & $3 \mathrm{~mm}$ ancho & $4 \mathrm{~mm}$ ancho \\
\hline 20 grs. & 32 grs & 16 grs. \\
\hline
\end{tabular}

En la muestra se observó la presencia de tres colgantes de una consistencia más delgada y una conformación ligeramente curva. A juzgar por su consistencia, es factible que estas pertenecerían a alguna concavidad de indole craneal de origen animal. Su estado de conservación muestra fragmentos que fueron adheridos conformando piezas más completas. En su manufactura evidencian contornos de bordes que han sido trabajados por la mano del hombre, logrando un redondeado en sus extremos, siendo más notorio en el extremo inferior, mientras que en la parte superior del soporte presenta dos orificios cuya función a juzgar se trataria de colgantes, en uno de ellos en la esquina del soporte óseo denota un faltante. Mientras que para el colgante $\mathrm{C}$ fue notorio identificar la presencia de un corte recto en su manufactura observado en el extremo inferior. Dicho material posteriormente de su documentación fue inscrito y registrado en el Ministerio de Cultura, con la finalidad de legalizar la colección y conformar un museo en memoria de don Max Díaz. registrados durante las actividades de Catalogación y Registro de Bienes Culturales, en el año 2010 en la ciudad de Lima.

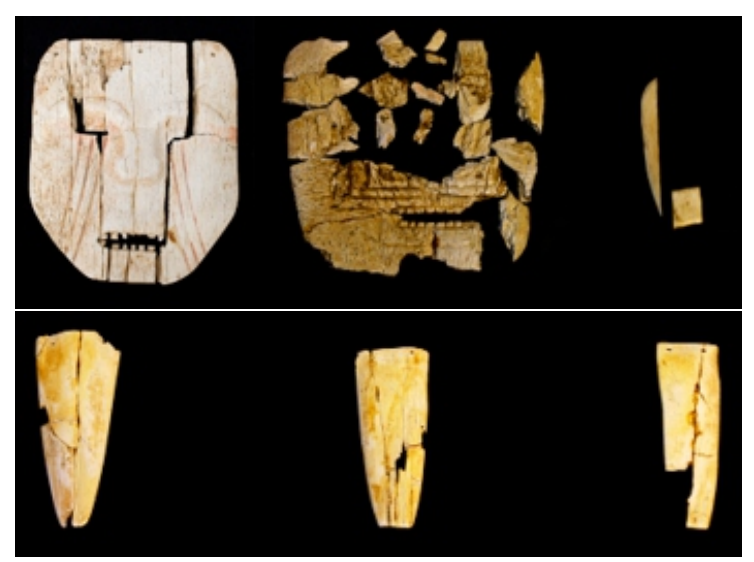

Lamina $\mathrm{N}^{\circ} 2$ Material óseo de origen paleontológico.

\section{RESULTADOS}

Ante la singularidad de las muestras óseas estudiadas, el diseño de investigación tambien estuvo orientado hacer un reconocimiento del área de donde estos provenían, a fin de constatar la fuente de información y correlacionar analogicamente de donde provienen las muestras óseas de origen paleontológico. Por los datos verbales recogidos su ubicación estaba descrita para la zona de Pampa La Pascona Alta, proximo al tramo del canal intervalle, área que se encuentra limitando por el noreste con el Cerro denominado Tres Cruces, por el sureste con Quebrada del Oso, por el oeste con un lecho de deyección (direccionado hacia los campos de cultivos del poblado de Chicama), y finalmente por el sur con un cauce proveniente de la quebrada del Oso. 
Los objetivos de la investigacion estuvo centrada en los materiales y un reconocimiento en el valle Chicama, en razon a que este fue considerado por varios estudiosos como cuna de la alta cultura, en razón a que contiene un rico depositario de testimonios arqueológicos que dan cuenta sobre la dispersión espacial, profundidad temporal y característica contextual de los distintos sistemas socio-culturales que la ocuparon y se desarrollaron en esta parte del territorio en la costa norte de Perú (Larco 1948, Kosok 1965).

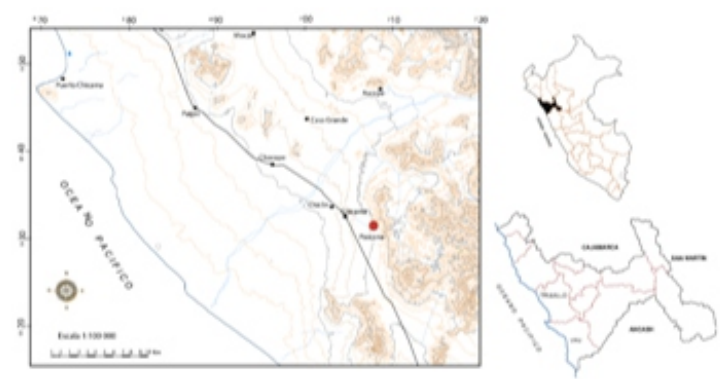

Lamina $\mathrm{N}^{\circ} 1$ Ubicación del sitio en el valle Chicama.

La justificación fue motivada por la presencia de un material unico en su genero, donado a Franjo Kurtovic Díaz nieto de don Máximo R. Díaz Díaz (fundador y primer director del Museo Arqueología, Antropología e Historia de la Universidad Nacional de Trujillo quien por encargo del rectorado en 1939), la donacion se realizo cuando se conmemoraba los 70 años de la fundación y la creación del museo de la UNT, época en que se venía reuniendo material arqueológico que se encontraba disperso entre los herederos del fundador en mención.

De la visita realizada al lugar, se observo que el entorno inmediato del espacio descrito, se trataba de una superficie plana y arenosa, cuyas inmediaciones proyectadas van hacia el este, observándose un pedregal de cantos rodados con evidente actividad de haber sido disturbado, limitando al oeste de la intersección del sistema hidráulico del canal intervalle. Área que descrita como probable lugar de hallazgo al cual antecede una loma, que a juzgar por la distribución de pequeños fragmentos óseos, se consideró que dichos objetos cayeron cuando alguien las transportaba, las referencias de huellas apenas visible era factible que se trataba de un probable equino, evidencias según la referencia subsistían a lo largo de un trecho de 20 metros y que el área estaba protegida por una loma apenas visibles que no permitió ser borradas por el viento y direccionadas de este a oeste, siendo factible hacia el poblado de Chicama. A considerar por el estado de conservación de los restos óseos y debido a la fragilidad y fragmentación que exteriorizan, denotan que permanecieron expuestos mucho tiempo a la intemperie. Fue infructuosa la labor de identificar algún detalles arquitectónicos en el área descrita, por lo que consideramos que los aspectos constructivos estarían un poco más distante de esta zona, es decir del otro lado del cerro Tres Cruces.

\section{DISCUSIÓN}

De los aportes de Bird (1985), dando cuenta de un arte primitivo relacionado al Precerámico costeño y el reporte de Vergara (1990), respecto a espátula que presentando a un personaje masculino en perfil, de labios y nariz engrosados, apertura la presencia de una iconografia de detalles singulares que revisten de importancia por las caracteristicas que presentaban. El análisis de los soportes óseos, permitió identificar que se hicieron orificios para ser sujetados o colgados, siendo factible que estas fueran empleadas como mascaras suntuarias de carácter mortuorio, a juzgar por la expresión con lagrimales nos recuerda a las representaciones culturales Sechín.

Si bien a la fecha no se ha encontrado un contexto arqueológico, tampoco se ha documentado antecedente alguno respecto a soportes con similares características, sin embargo en razón a su singularidad conllevo a buscarles un ordenamiento cronológico, e ir fundamentando elementos identificatorios y comparativos. A través de las bases analógicas y por los rasgos elementales de semejanza, que nos permiten sostener que estarían relacionados dentro la producción de una plástica visual temprana, identificada al estilo cultural Sechín, cuya antigüedad según Bischof (2009: 9), va desde los (3400-1650 a.C.), y contemporáneas cronológicamente al Arcaico Tardío (2500 a.C.) en la costa norte, entendiéndose que en este período se venía gestando modalidades primigenias de formas y profusión de creencias, así como a la conceptualización de un universo de simbologías y a la interacción de concepciones religiosas tal como Kauffman (1973) deja entrever en sus publicaciones.

Todo hace indicar que la movilidad de grupos humanos cada cierta época; articulaban espacios considerados paisajes sagrados, donde se aprovechaban del recojo de alimentos en las lomas, así tenemos que varios sitios del valle Chicama cambia el entorno de su aridez debido a fenómenos hidroclimáticos que temporalmente ocurren. Siendo factible que el sitio "Cerro Tres Cruces" cumpliera esa función de ser un relicto de convocatoria ancestral. En base a reportes realizados pertenecientes a la filiación cultural Cupisnique (1800 a.C.), presentes en sus laderas existiendo caminos, arquitectura temporal elaborada con piedras, tambien presente un geoglifo con la representación de un ave teniendo las alas expandidas 
que alcanza 40 metros de largo (Gálvez, et: tal, 2012: $91)$, la representación visual da una connotación especial al paisaje y requiere de mayores estudios, a fin de comprender mejor esta parte del valle. Si bien a la fecha en el valle Chicama, no se ha encontrado arquitectura monumental que permita relacionarlo directamente con el estilo Sechín, como si se reporta en el valle Moche con la presencia de Huaca Caballo Muerto (Pozorki 1976).

El resultado de nuestras investigaciones en el sitio denominado Alto de la Guitarras, se ha identificado representaciones visuales graficadas sobre la superficie de soportes rocosos como pertenecientes tambien al estilo Sechín, se trata de un soporte grande en sus dimensiones que a juzgar por su conformación de rasgos, consideramos estrechamente relacionado con elementos al estilo Sechín, se trata de una cabeza redondeada, nariz ancha y una boca de labios gruesos.

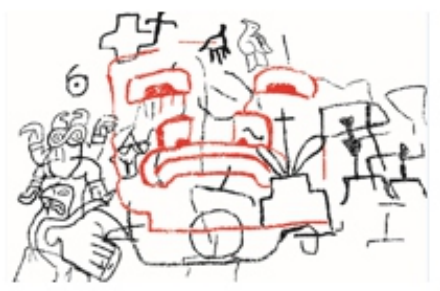

Lamina $\mathrm{N}^{\circ} 7$ En color rojo para diferenciar el motivo Sechín presente en el sitio denominado como el Alto de la Guitarra,

En lo que respecta al valle Virú, se constato que el aspecto constructivo de huaca "San Juan", permite cotejar aspectos constructivos analogicamente con similitud a la arquitectura monumental presente en el sitio de Sechín bajo en el valle Casma en la costa central. Basados en las apreciaciones del Dr. Julio C. Tello (1956), quien identificó inicialmente las características del estilo Sechín, para el valle de Casma, en base a los rasgos que estos presentaban como es la cabeza redondeada, lagrimales, nariz ancha entre otros detalles que tambien reportadas posteriormente por Kauffman (1973) presentando imágenes en su manual de arqueología peruana, con las características iconográficas ya mencionadas.

\section{CONCLUSIONES}

El resultado del estudio de los soportes óseos en la colección "Max Diaz", nos permite desglosar que es factible que el hombre en sus continuos desplazamientos por esta parte del territorio y muy tempranamente haya manipulado, manufacturado los restos óseos de origen paleontológico, a dichos soportes les dieron una connotación especial, como adornos suntuarios, es factible que evocaran una escala de sus valores y alimentára mitos cosmogónicos, dando respuesta a una visión integradora de su mundo.

A juzgar por los rasgos elementales que presentan los soportes óseos, nos permiten relacionarlos estilisticamente como manufacturas identificadas cronologicamente al estilo Sechín; entendiendose que para este período del Arcaico Tardío (2500 a.C.), se estaba gestando diversas modalidades artísticas, resultado de creencias e interacción con las esferas religiosas e ideológicas.

Dejar constancia de agradecimiento a Franjo Kurtovic Díaz, que permitió la documentación de dicho material y el inventario de piezas heredadas.

\section{REFERENCIAS BIBLIOGRÁFICAS}

BISCHOF, H. 2009. Los Períodos Arcaico Tardío, Arcaico Final y Formativo Temprano en el valle de Casma: evidencias e hipotesis. En: Boletín de Arqueología. Pontificía Universidad Catolica del Perú. Revista N¹3 pp.9-54 Lima Perú.

BIRD J. 1985, The preceramic excavations at the Huaca Prieta Chicama Valley, Perú. Anthropological Papers of The American Museum of Natural History Volume 62, $\mathrm{N}^{\circ} 1$. New York.

GALVEZ, C et: tal, 2012. Geoglifos, ocupación y uso del espacio en el valle Medio de Chicama, Costa Norte del Perú.

KAUFFMAN F. 1973. Manual de arqueologìa Peruana. Ediciones Peisa. Lima

KOSOK P. 1965, Life, Land and Water in Ancient Peru. Long Island University Press. New York

LARCO R. 1948, Cronologìa Arqueologìca del Norte de Perú. Sociedad Geogràfica Americana. Impreso Buenos Aires Argentina

TELLO, J. 1956 Arqueología del valle de Casma. Culturas: Chavín, Santa o Huaylas Yunga y Sub-Chimú. Informe de los trabajos de la Expedición Arqueológica al Marañón de 1937, Publicación Antropológica del Archivo Julio C. Tello de la Universidad Nacional Mayor de San Marcos, Lima.

VERGARA, E. 1990, Novedades Arqueológicas del Museo. Espátulas de hueso de la Cultura Chavín. En: Revista del Museo de arqueología No. 1, Universidad Nacional de Trujillo-pp. 111 